\title{
PREOPERATIVE ANALYSIS OF RADIOGRAPHIC FINDINGS IN 516 PATIENTS WITH HALLUX VALGUS DEFORMITY
}

\author{
ANÁLISE PRÉ-OPERATÓRIA DE ACHADOS RADIOGRÁFICOS EM \\ 516 PACIENTES COM DEFORMIDADE DE HALLUX VALGUS
}

\author{
Marco Götze ${ }^{1}$, Sandra Elisabeth Hasmann ${ }^{2}$, Ulf Krister Hofmann ${ }^{1}$, Christian Walter ${ }^{1}$, Falk Mittag ${ }^{1}$ \\ 1. Department of Orthopaedic Surgery, University Hospital Tübingen, Tübingen, Germany. \\ 2. Department of Internal Medicine IV, Ludwig-Maximilians-University Munich, Munich. Germany.
}

\begin{abstract}
Objective: This is a descriptive study to report our method of operative correction for patients with hallux valgus deformities. Methods: From 2006 to 2012, 516 consecutive patients (601 feet) with hallux valgus deformities were treated surgically in our department after conservative treatments were exhausted. The hallux valgus angle, intermetatarsal angle, distal metatarsal articular angle, and degree of osteoarthritis in the first metatarsophalangeal joint were measured on preoperative plain radiographs of the weight-bearing forefoot. Results: Young patients with severe intermetatarsal deviation received a combined proximal and distal osteotomy of the first metatarsal $(n=21)$. Patients with low intermetatarsal deviation received a distal metatarsal chevron osteotomy $(n=196)$, whereas patients with severe intermetatarsal deviation and less flexible deformities without osteoarthritis received a basal metatarsal osteotomy with a distal soft tissue procedure $(n=173)$. Elderly active patients with osteoarthritis in the first metatarsophalangeal joint received an arthrodesis $(n=100)$ or resection arthroplasty $(n=58)$. Conclusion: Determining a few simple angles on plain radiographs of the weight-bearing forefoot in combination with the age and level of activity of patients can help simplify the operative correction method by using the schema we developed. Level of evidence IV, case series.
\end{abstract}

Keywords: Hallux valgus. Radiography. Reoperation.

\section{RESUMO}

Objetivo: Este é um estudo descritivo para relatar nosso método de correção cirúrgica para pacientes com deformidades de hálux valgo. Métodos: De 2006 a 2012, 516 pacientes consecutivos (601 pés) com deformidade de hálux valgo foram tratados cirurgicamente em nosso departamento, depois que os tratamentos conservadores foram esgotados. O ângulo do hálux valgo, o ângulo intermetatarsal, o ângulo articular metatarsal distal e o grau de osteoartrite da primeira articulação metatarsofalângica foram medidos em radiografias pré-operatórias simples do antepé com apoio de peso. Resultados: Os pacientes jovens com desvio intermetatarsal grave foram submetidos à combinação de osteotomia distal e proximal do primeiro metatarso $(n=21)$. Os pacientes com desvio intermetatarsal menor foram submetidos a osteotomia de Chevron no metatarso distal $(n=196)$, enquanto que os pacientes com desvio intermetatarsal grave e deformidades menos flexiveis e sem osteoartrite foram submetidos a osteotomia da base do metatarso com um procedimento distal no tecido mole $(n=173)$. Nos pacientes idosos ativos com osteoartrite na primeira articulação metatarsofalângica realizou-se artrodese $(n=100)$ ou artroplastia de ressecção $(n=58)$. Conclusão: Determinar alguns ângulos com radiografias simples do antepé com apoio de peso em combinação com idade e nível de atividade dos pacientes pode ajudar e simplificar o método de correção cirúrgica, usando o esquema que desenvolvemos. Nível de Evidência IV, Série de casos.

Descritores: Hallux Valgus. Radiografia. Reoperação.

Citation: Götze M, Hasmann SE, Hofmann UK, Walter C, Mittag F. Preoperative analysis of radiographic findings in 516 patients with hallux valgus deformity. Acta Ortop Bras. [online]. 2019;27(1):16-9. Available from URL: http://www.scielo.br/aob.

\section{INTRODUCTION}

Hallux valgus is the most common forefoot deformity presenting to foot and ankle surgeons, often accompanied by foot pain and severe functional constraint. The global prevalence, as described in the international literature, is $23 \%$ in 18 to 65 year old patients and up to $35 \%$ in elderly over 65 years of age. ${ }^{1}$ It has been widely reported, that women are more often affected than men - there are female / male ratios reported up to a level of $15: 1 .^{2}$ The valgus deformity can be caused by multiple exogenous and endogenous factors such as wearing of tight and high-heeled shoes or genetic predisposition. ${ }^{3-6}$ Diagnosis of hallux valgus is achieved by clinical examination. A plain radiograph of the weight bearing foot is required additionally. There still is no consensus about which clinical and

All authors declare no potential conflict of interest related to this article.

Study was conducted at the Department of Orthopaedic Surgery in Tübingen, Germany.

Correspondence: Priv.-Doz. Dr. Falk Mittag. Department of Orthopaedic Surgery, University Hospital Tübingen, Hoppe-Seyler-Str. 3, 72076 Tübingen, Germany.

falk.mittag@med.uni-tuebingen.de 
radiographic findings lead to the indication of which method of operative correction of hallux valgus. ${ }^{7-10}$

We report our experience with special regard to the correlation of radiographic findings and resulting method of operative correction of the valgus deformity by developing a schema that helps to determine the correct indication.

\section{MATERIALS AND METHODS}

From 2006 to 2015, five hundred sixteen consecutive patients (601 feet) with a hallux valgus deformity were treated surgically in our university hospital orthopaedic department after exhausted conservative treatment. None of the patients had undergone prior surgery to the forefoot or suffered from concomitant diseases. The same board of surgeons in all presented cases chose indication for the method of operative correction.

Retrospectively, preoperative plain radiographs of the weight bearing foot were analysed. We measured the hallux valgus angle (HVA), the intermetatarsal angle (IMA), and the distal metatarsal articular angle (DMAA). Further we evaluated the radiographic signs of osteoarthritis in the first metatarsophalangeal (MTP) joint using the standard radiographic classification with stages from 0 to 3 , stage 0 showing no signs of degeneration, stage 3 being a severe osteoarthritis with a loss of joint space. ${ }^{11}$ The radiographs were read by the same board of surgeons indicating surgery. The length of the first and second metatarsal was measured to determine a protrusion of the first metatarsal and to calculate the MT-index, as described by Hardy and Clapham with a positive value meaning a longer first metatarsal (index plus type) and a negative value with a longer second metatarsal (index minus type). ${ }^{12}$ The MT-index did not affect the decision on the operative method to correct the hallux valgus deformity, but often lead to additional procedures like distal metatarsal shortening in patients with severe metatarsalgia and an index minus type. However, in special cases with severe metatarsalgia and an index minus type, we performed an arthrodesis of the first metatarsophalangeal joint to functionally lengthen the first ray. As shown in Figure 1, the methods of operative correction used in our department were either the distal chevron first metatarsal osteotomy, the proximal open-wedge reverse chevron metatarsal osteotomy with medial bone impaction and single screw stabilization combined with a distal soft-tissue procedure to release the lateral MTP-I joint capsule and the adductor hallucis tendon, the combined proximal and distal osteotomy of the first metatarsal, the arthrodesis of the first metatarsophalangeal joint using a dorsal plate and a plantar neutralization screw, the Keller-Brandes resection arthroplasty of the distal part of the first metatarsophalangeal joint with interposition of a capsular flap and temporary wire fixation, or the combined proximal osteotomy of the first metatarsal and Keller-Brandes resection arthroplasty of the distal part of the first metatarsophalangeal joint with interposition of a capsular flap with temporary wire fixation.

All patients undergoing hallux valgus correction surgery were postoperatively treated with full weight bearing in a special forefoot relief shoe for 6 weeks.

In the statistical analysis data are presented with the mean and standard deviation or with frequency in percentage. P-values were assessed using Analysis of Variance (ANOVA) or Pearson's Test. Differences between the groups were assessed by post-hoc Student's t-Test. The level of significance was set at alpha $=0,05$. Bonferroni correction was used in multiple comparisons, with alpha then set at $0,008(0,05 / 6)$.

The research presented in this work conforms to the Helsinki Declaration and to local legislation. It has been approved by the ethical committee.
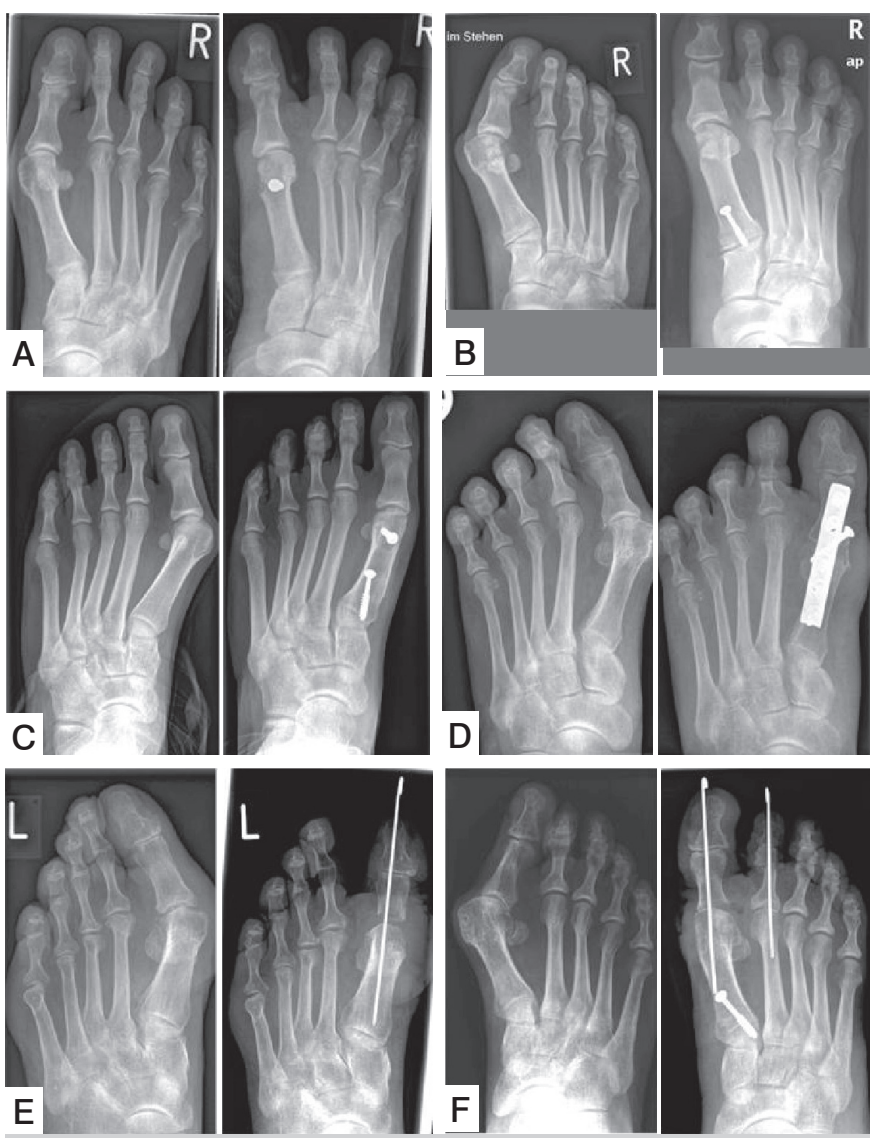

Figure 1. Pre- and postoperative radiographs 6 weeks after hallux valgus correction surgery. a) chevron osteotomy metatarsal-I; b) basal osteotomy of metatarsal-I with distal soft tissue procedure; c) distal and proximal double osteotomy of metatarsal-I; d) arthrodesis of metatarsophalangeal-I joint; e) resection arthroplasty of metatarsophalangeal -I joint; f) combined resection arthroplasty and basal osteotomy of metatarsal-I

\section{RESULTS}

The results are illustrated in Table 1. Five hundred sixteen consecutive patients underwent operative correction of their Hallux valgus deformity in our department between 2006 and 2015. 453 of the patients were female $(87,8 \%)$ with 531 feet, 63 were male $(12,2 \%)$ with 70 feet, which is a significant female / male ratio of approximately $7: 1$ ( $p=0,0105$, Pearson). The median age of a male patient at the time of surgery was 54,5 years (range 16 to 77 years), while the median age of a female patient was 58 years (range 11 to 90 years). 310 times we performed surgery on the left foot, 291 times on the right foot.

The preoperative mean hallux valgus angle measured in plain radiographs was 34,5 degrees (SD 9,61; range 12-74). Overall the patients had a mean preoperative intermetatarsal angle of 15,5 degrees (SD 3,78; range 3-33). The mean distal metatarsal articular angle measured preoperatively was 17,5 degrees (SD 10,67; range 0-77). The mean radiographic stage of osteoarthritis was 1,3 (SD 0,80). In men, 16 feet showed no sign of degeneration at all, 25 feet were rated a mild stage 1 osteoarthritis with preservation of joint space, another 25 feet were a stage 2 osteoarthritis with joint space narrowing and 4 feet showed a severe radiographic osteoarthritis with loss of joint space. In 453 female patients, 90 feet showed no joint degeneration, 230 feet were rated a stage 1 mild osteoarthritis, 186 feet showed a stage 2 osteoarthritis with joint space narrowing and 25 feet showed a significant osteoarthritis with loss of joint space. 
Table 1. Demographics and corresponding radiographic findings by methods of surgical correction.

\begin{tabular}{|c|c|c|c|c|c|c|c|}
\hline & DOT $\left(^{*}\right)$ & COT (\#) & BOT (§) & ART (+) & $\operatorname{RAP}(\&)$ & BOT+RAP & $p$-value \\
\hline $\mathrm{N}$ feet (percentage) & $21(4 \%)$ & $196(33 \%)$ & $173(29 \%)$ & $100(17 \%)$ & $58(10 \%)$ & $53(9 \%)$ & \\
\hline OA [degree 0 to 3] & $0,57(0,15)$ & $0,82(0,05)$ & $\begin{array}{c}1,31(0,05) \\
\text { *\# }\end{array}$ & $\begin{array}{c}1,83(0,07) \\
\star \# \S\end{array}$ & $\begin{array}{c}1,62(0,09) \\
* \# \S\end{array}$ & $\begin{array}{c}1,72(0,10) \\
* \# \S\end{array}$ & $<0,0001$ \\
\hline HVA [angle] & $40,57(1,78)$ & $\underset{\star}{27,59}(0,59)$ & $\begin{array}{c}36,13(0,26) \\
\#\end{array}$ & $\begin{array}{c}39,77(0,82) \\
\# \S\end{array}$ & $\begin{array}{c}35,21(1,07) \\
\#+\end{array}$ & $\begin{array}{c}41,45(1,12) \\
\# \S \&\end{array}$ & $<0,0001$ \\
\hline DMAA [angle] & $29,86(10,57)$ & $15,98(10,77)$ & $15,67(7,08)$ & $18,23(12,85)$ & $16,77(9,31)$ & $\begin{array}{c}21,75(12,67) \\
* \# \S\end{array}$ & $<0,0001$ \\
\hline
\end{tabular}

Data are presented with number (percentage) or mean (standard deviation). P-values were assessed with Analysis of Variance (ANOVA) or Pearson's Test. Significance level was set at alpha $=0,008$ (after Bonferroni correction by number 0 groups: 0,05/6). Differences between the groups were assessed by post-hoc Student $s$ t-Test. Significant differences between particular groups are shown by the special characters: ${ }^{*}$, \#, $\$$, + and \&. N: number; DOT: Double osteotomy

OA: degree of osteoarthritis; HVA: Hallux valgus angle; IMA: Intermetatarsal angle; DMAA: Distal metatarsal articular angle

The mean preoperative length of the first metatarsal in our patients was $5,7 \mathrm{~cm}$ (SD 0,49; range 3,2-7,3), calculating the MT-index resulted in a mean of $0,45 \mathrm{~cm}(\mathrm{SD} 0,31)$ index plus type. Only 2 male feet showed a negative MT-index value (2,9\%), meaning an index minus type with a longer second metatarsal and only 6 male feet showed an index plus minus type with an equal length of the first and second metatarsal (8,6 \%). Only 13 female feet presented a preoperative index minus type with a negative MT-index value (2,4\%), 40 female feet showed an index plus minus type $(11,4 \%)$.

A combined proximal and distal osteotomy of the first metatarsal was only performed in young patients with an age of 29,9 years (SD 14,95). These patients had very mild signs of osteoarthritis with 0,6 $(S D 0,15)$. The HVA on the other hand was very high in this group with 40,6 (SD 1,78), as well as high values of the IMA with 18,1 (SD $0,74)$. The DMAA was by far the highest in this group of patients with 29,9 degrees (SD 10,57).

The distal chevron metatarsal osteotomy was mainly performed in younger patients with a mean age of 44,2 years (SD 15,25). These patients presented only mild radiographic signs of osteoarthritis with 0,8 (SD 0,06). The HVA and the IMA were the lowest in this group with 27,6 degrees (SD 0,59) and 13,5 (SD 0,24), as well as close to the lowest values for the DMAA with 16,0 degrees (SD 10,77).

The proximal open-wedge reverse chevron metatarsal osteotomy with medial bone impaction and single screw stabilization combined with a distal soft-tissue procedure was performed in middle aged patients with moderate signs of osteoarthritis, which was 1,3 (SD $0,05)$. The HVA was 36,1 degrees (SD 0,62) and the IMA 16,8 degrees $(S D 0,26)$. The DMAA was the lowest in this group of patients with a mean of 15,7 degrees (SD 7,08). The age of the patients at the time of surgery was 54,2 years (SD 10,76).

In patients having received an arthrodesis of the metatarsophalangeal joint, the radiographic signs of osteoarthritis were high with a mean of 1.8 (SD 0,07). The HVA values were high with 39,8 degrees (SD 0,82). The IMA was average with 16,0 degrees (SD 0,34), as well as the DMAA with 18,2 degrees (SD 12,85). At the time of surgery patients in this group were 61,8 years old (SD 10,52).

Keller-Brandes resection arthroplasty of the first metatarsophalangeal joint was only performed in elderly patients. The patients in this group were 72,6 years old (SD 5,70). They showed higher signs of osteoarthritis, which were 1,6 (SD 0,09). The HVA was 35,2 (SD 1,07), whereas the overall IMA and DMAA were close to the lowest in this group with means of 13,7 degrees (SD 0,44) and 16,8 degrees (SD 9,31).

The combined proximal osteotomy of the first metatarsal and KellerBrandes resection arthroplasty of the first metatarsophalangeal joint was performed only in elderly female patients with a mean age of 72,9 years (SD 5,41). They showed higher signs of osteoarthritis with 1,7 (SD 0,10) and had the highest values for the HVA with 41,5 degrees (SD 1,12) and the IMA with 18,1 degrees (SD 0,46). The DMAA values also were quite high with 21,8 degrees (SD 12,67). Under consideration of these demographic, radiologic and clinical findings the indication for a particular method of operative correction was set.

The first decision to make was whether to preserve the first metatarsaophalangeal joint in patients with sigs of osteoarthritis. If this is not possible and it had to be sacrificed, it is important to consider the individual patients level of activity. In younger active patients we perform an arthrodesis of the first MTP joint to achieve good function regarding the heel-to-toe movement. In elderly non-active patients we recommend a Keller-Brandes resection arthroplasty of the distal part of the MTP-I joint. Advantages are the faster recovery and fewer possible complications like non-unions. It is important to consider the intermetatarsal angle in these patients as we suggest combining this procedure with a basal osteotomy of the first metatarsal to narrow the fore foot if it shows values of 15 degrees or higher.

If there are no signs of osteoarthritis we preserve the first MTP joint. It then is important to evaluate the congruence of the joint. If the radiograph shows a congruent joint, we suggest performing a distal chevron osteotomy of the first metatarsal and single screw fixation. In patients with a congruent but more deviated joint surface presenting with a distal metatarsal articular angle of higher than 10 degrees, we recommend to excide a medial wedge. In younger patients with severe deviation, this often is not sufficiently leading to a satisfying correction, so we suggest combining it with a second basal osteotomy of the first metatarsal in presence of intermetatarsal angles of 15 degrees or higher to narrow the fore foot.

If on the other hand the radiographs show an incongruence of the first MTP joint, we need to perform a distal soft tissue procedure to release the lateral MTP-I joint capsule and the adductor hallucis tendon and correct the position of the first ray. Yet again we suggest to consider the intermetatarsal angle and to perform a basal osteotomy of the first metatarsal on addition in patients with values of 15 degrees and higher.

These results are summed up in Figure 2, a schema we developed in our department. It represents a simple algorithm to work out the correct method of operative correction using above-named radiographic signs and angles.

\section{DISCUSSION}

No other forefoot deformity is as common as the hallux valgus. Our data supports the international literature with a higher incidence in women with a ratio of 7:1 in our collective. There have been described over 150 methods of operative correction. The choice of which operative method to use is made individually in due consideration of the 


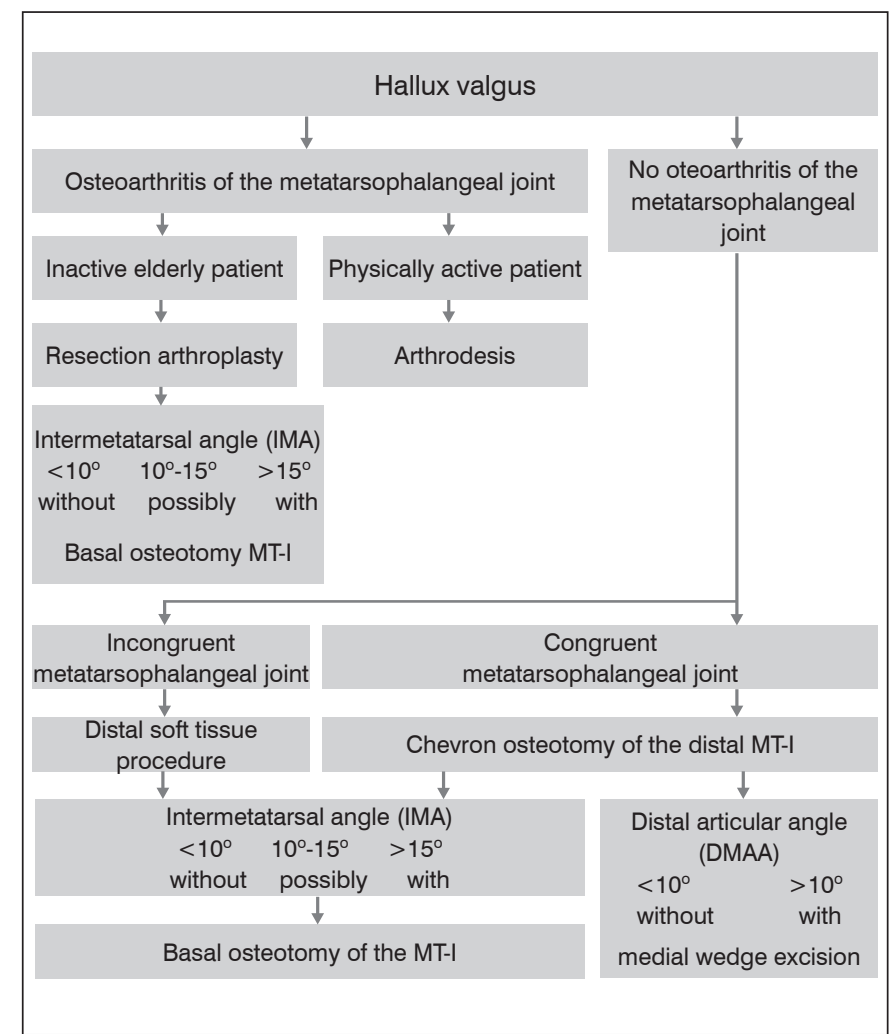

Figure 2. Treatment algorithm for operative correction of the Hallux valgus, modified Wulker schema ${ }^{13}$. particular deformity and the patient's clinical and social presentation. Therefore it is particularly difficult to conduct randomized clinical trials comparing different operative techniques. ${ }^{7-10}$ Reviewing the literature, most authors compared operative techniques being very similar to another or comparing specific details of operative methods. Considering the huge variety of operative techniques and the low level of evidence in the existing literature it is challenging to give the precise indication for the individual patient. In general we indicate operative correction in patients with pain within the first ray, metatarsalgia or the development of symptomatic lesser toe deformities caused through hallux deviation. Conservative treatment has to be exhausted. The purpose of surgery mainly in younger patients is to restore the physiological anatomy of the foot. In elderly patients the main purpose is to improve function and minimize pain, often by sacrificing the first metatarsophalangeal joint through resection or arthrodesis. ${ }^{13}$

\section{CONCLUSION}

The present study does not value postoperative results of the mentioned methods of operative treatment. This is a descriptive study to report our experience and show the difficulty and our way of indicating the method of operative correction for patients with hallux valgus deformities in its variety. Determining a few simple angles in a plain radiograph of the weight bearing fore foot in synopsis with the age and level of activity of a certain patient can help and simplify indicating the correct method of operative correction using the schema we developed. There is a variety of operative methods to treat the diversity of hallux valgus deformities. Each surgeon needs to command several of these methods to be able to treat each individual patient sufficiently. It is essential to consider every facet of the patient, clinical and radiographic findings as well as the social life and activity.

AUTHORS' CONTRIBUTIONS: Each individual author contributed individually and significantly to the development of this work. MG (0000-0001-5310-9016) participated in collecting data and drafting the manuscript; SH (0000-0002-9666-6311)*: participated in in study design and statistical analysis; UH (00000003-0589-6654)*: participated in study design and finalizing the manuscript; CW (0000-0003-3724-6533)*: participated in study design and finalizing the manuscript; FM (0000-0002-0752-8532)* : participated in study design and drafting and finalizing the manuscript. *ORCID (Open Researcher and Contributor ID).

\section{REFERENCES}

1. Nix S, Smith M, Vicenzino B. Prevalence of hallux valgus in the general population: a systematic review and meta-analysis. J Foot Ankle Res. 2010;3:21.

2. Nery C, Coughlin MJ, Baumfeld D, Ballerini FJ, Kobata S. Hallux valgus in males-part 1: demographics, etiology, and comparative radiology. Foot Ankle Int. 2013;34(5):629-35.

3. Wulker N. [Hallux valgus]. Der Orthopade. 1997;26:654-64.

4. Perera AM, Mason L, Stephens MM. The pathogenesis of hallux valgus. J Bone Joint Surg Am. 2011;93(17):1650-61.

5. Nguyen US, Hillstrom HJ, Li W, Dufour AB, Kiel DP, Procter-Gray E, et al. Factors associated with hallux valgus in a population-based study of older women and men: the MOBILIZE Boston Study. Osteoarthritis Cartilage. 2010;18(1):41-6.

6. Mann RA, Coughlin MJ. Hallux valgus--etiology, anatomy, treatment and surgical considerations. Clin Orthop Relat Res. 1981;(157):31-41.

7. Saro C, Andren B, Wildemyr Z, Fellander-Tsai L. Outcome after distal metatarsal osteotomy for hallux valgus: a prospective randomized controlled trial of two methods. Foot Ankle Int. 2007;28(7):778-87
8. Klosok JK, Pring DJ, Jessop JH, Maffulli N. Chevron or Wilson metatarsal osteotomy for hallux valgus. A prospective randomised trial. J Bone Joint Surg Br. 1993;75(5):825-9

9. Faber FW, Mulder PG, Verhaar JA. Role of first ray hypermobility in the outcome of the Hohmann and the Lapidus procedure. A prospective, randomized trial involving one hundred and one feet. J Bone Joint Surg Am. 2004;86-A:486-95.

10. Deenik A, van Mameren $H$, de Visser $E$, de Waal Malefijt M, Draijer F, de Bie R. Equivalent correction in scarf and chevron osteotomy in moderate and severe hallux valgus: a randomized controlled trial. Foot Ankle Int. 2008;29(12):1209-15.

11. Hattrup SJ, Johnson KA. Subjective results of hallux rigidus following treatment with cheilectomy. Clin Orthop Relat Res. 1988;(226):182-91.

12. Hardy RH, Clapham JC. Observations on hallux valgus; based on a controlled series. J Bone Joint Surg Br. 1951;33-B:376-91.

13. 1 Wulker N, Mittag F. The treatment of hallux valgus. Dtsch Arztebl Int. 2012;109(43):857-68 